\title{
BMJ Open Not engaged in education, employment or training (NEET) in an Arctic sociocultural context: the NAAHS cohort study
}

\author{
Elisabeth Valmyr Bania, ${ }^{1}$ Christian Eckhoff, ${ }^{2,3}$ Siv Kvernmo ${ }^{2,3}$
}

To cite: Bania EV, Eckhoff C, Kvernmo S. Not engaged in education, employment or training (NEET) in an Arctic sociocultural context: the NAAHS cohort study. BMJ Open 2019;9:e023705. doi:10.1136/ bmjopen-2018-023705

- Prepublication history for this paper is available online. To view these files, please visit the journal online (http://dx.doi. org/10.1136/bmjopen-2018023705).

Received 23 April 2018 Revised 11 December 2018 Accepted 16 January 2019

Check for updates

(C) Author(s) (or their employer(s)) 2019. Re-use permitted under CC BY-NC. No commercial re-use. See rights and permissions. Published by BMJ.

${ }^{1}$ Department of Mental Health, NTNU, Trondheim, Norway

${ }^{2}$ Child and Adolescent Psychiatry, University Hospital of North Norway, Troms $\emptyset$, Norway ${ }^{3}$ Department of Clinical Medicine, UiT The Arctic University of Norway, Troms $\emptyset$, Norway

Correspondence to Dr Elisabeth Valmyr Bania; elisabeth.bania@ntnu.no

\section{ABSTRACT}

Objectives The purpose of the study is to explore the prevalence and predictors of not engaged in education, employment or training (NEET) status in a multicultural young adult population in Northern Norway.

Design and setting The longitudinal design link a selfreported survey (2003-2005) with an objective registry linkage follow-up 8-10 years later.

Participants Of all 5877 tenth graders (aged 15-16 years) in Northern Norway, $83 \%$ of the total age cohort from all 87 municipalities participated in the baseline survey. The follow-up studies consisted of 3987 consent giving adolescents $(68 \%)$, were $365(9.2 \%)$ reported indigenous Sami ethnicity.

Outcome measures Youth NEET at the age of 23-25 years.

Methods Explanatory variables were sociodemographic factors (gender, ethnicity, residency, parental education), mental health problems and musculoskeletal pain in adolescence. Outcome variable characterised as NEETstatus was defined by no educational engagement, longterm recipient of sickness benefit, medical and nonmedical benefit receipt or long-term unemployment.

Results NEET-status in young adulthood was significantly higher among females (20.9\%) than among males (16.2\%). Ethnic differences occurred as being NEET among Sami males was significantly higher than among non-Sami males, $23.0 \%$ and $15.2 \%$ respectively. Minority Sami females experienced NEETstatus to a lower degree (16.6\%) than non-Sami females (20.8\%). Among females adolescent peer problems (adjusted $\mathrm{OR}=1.09$ ) and hyperactivity problems (adjusted $\mathrm{OR}=1.10$ ) were associated with later NEETstatus. Peer problems (adjusted $\mathrm{OR}=1.23$ ), conduct problems (adjusted $\mathrm{OR}=1.17$ ) and musculoskeletal problems (adjusted $\mathrm{OR}=1.15$ ) in male adolescents were associated with later NEET-status, whereas emotional problems among males predicted significantly less later NEET- status (adjusted OR=0.88). We found lower parental education to be significantly associated with being NEET-later in young adults (females: adjusted $\mathrm{OR}=2.11$, males: adjusted $\mathrm{OR}=3.22$ ).

Conclusions To address the disengagement of education and work, particular emphasis must be placed on supporting young people struggling with mental and physical health problems.

\section{Strengths and limitations of this study}

- The main strength is the linkage of a large population-based study in adolescence (2003-2005) to the National Education Database (2003-2012) and the National Insurance Registry (FD-Trygd) (2003-2012).

- The longitudinal design, based on a self-reported baseline survey and objective registry data linkage 8-10 years later, with high response rate, $(83 \%$ in survey), where $68 \%$ of the total age cohort gave consent for follow-up and where 9.2\% (survey) are indigenous Sami, and 10\% reported Sami ethnicity in follow-up study.

- The registry data linkage enabled us to follow the educational and work related footprints of young adults over a decade.

- The cross-sectional self- reported survey by adolescents has a risk of information bias.

- New concepts as being not engaged in education, employment or training can leave out youngsters at risk, and is not a completely objective outcome term.

\section{INTRODUCTION}

The term NEET (not engaged in education, employment or training) refers to young people who have dropped out of education, training or work, and who may not register as unemployed as there is little financial incentive to sign on as unemployed. ${ }^{1}$ Over time, young people who experience NEETstatus are at risk of permanent social exclusion. $^{2}$ Olsen and colleagues ${ }^{3}$ describe the term NEET, and its plural NEETs, as the acronym for 'not in education, employment or training'. The term NEET was coined by the UK Department for Education in 1999 which uses it for quarterly statistics. ${ }^{4}$ The age group covered by the UK statistics is from 16 to 18 years of age, but definitions may vary. In Japan, the term NEET is used for people of the broad age range, from 15 to $35 .^{5}$ Developed countries and high-income nations describe the disengagement among youth 
as concerning. ${ }^{6}$ The phenomenon is explained, understood and named differently with various cultural bound; as Japanese hikikomori, US slacker and the term NEET mostly used in Europe. ${ }^{78}$

The NEET term is questioned and criticised. ${ }^{910}$ Rightly so, new concepts need to be introduced, questioned and developed. ${ }^{5}$ NEET-status can be seen as a collective term for including youth who are vulnerable. ${ }^{1}$ The NEET concept can be a useful tool for targeting means of intervention. ${ }^{911}$ Oliver et $a l^{12}$ emphasises that interventions for engaging people experiencing NEET-status may work well in rural, but not urban areas, during economic growth and not retention, or in conservative but not liberal societies; in other words, a contextual term which can be applied also within the Organization for Economic Co-operation and Development (OECD) countries. ${ }^{25}$

This present study is designed for NEET-status in young Norwegians, including both majority ethnic Norwegians, and indigenous Sami Norwegians. Nordic researchers use the NEET term to describe youth marginalised from employment and education. ${ }^{3}$ Youth unemployment is of the greatest concern within the OECD. ${ }^{13}$ However, the OECD focus is expanded to include those not only not in education and employment but also those not in training with being NEET. ${ }^{14}$

Egalitarian Norway is a tax-funded, redistributive welfare state, with universal entitlements and generous contributions for social and financial security. ${ }^{15}$ The fiscal and ideological policy, with its Work Approach ${ }^{16}$ have shown to protect against crime and social injustice. ${ }^{15}$ However, the negative consequence can be that some young adults choose welfare benefits over employment and work-based income. ${ }^{17}{ }^{18}$ International studies suggest that recipients of social welfare benefits are associated with later work exclusion, or more lack of work inclusion. ${ }^{19}{ }^{20}$ Work is also an important source of social inclusion and affects health in a positive way. ${ }^{21}$ The individual and the society therefore, have an interest in youth starting adult life in education, employment or in training. ${ }^{17812}$

Work marginalisation can be defined as being on the border of the labour market. ${ }^{10}$ The person is not fully integrated in, but not permanently excluded from, the labour market. ${ }^{22}$ In empirical research, the common source of data used to study marginalisation has been information on unemployment, long-term absence by sick-leave and social-welfare benefit receipt. ${ }^{123}$ Normann et $a l^{22}$ explained how work marginalisation can be viewed from an individual or from a sociocultural perspective, as well as a sociological perspective. ${ }^{20}$ The work approach as a norm in society, means that most individuals will be integrated into the labour force. ${ }^{23}$ However, some people may for different reasons, voluntarily choose not to participate in the labour force. ${ }^{15}$

In general, individuals with less education or income, and who are unemployed report poorer health. ${ }^{24}$ Norwegians are in general reported to be in good health, compared with the OECD average; $73 \%$ vs $69 \%$, respectively. ${ }^{25}$ In spite of this, Norway has the highest incidence of sickness absence and greatest disability caseload in the OECD. ${ }^{25}$

Of all young people in Norway, $6.3 \%$ received social welfare benefits within a year and for at least a 1 month period. More than $60 \%$ of the recipients were single person households. ${ }^{26}$ According to Statistics Norway the number of social welfare benefit recipients has been stable since $2005 .{ }^{27}$ Young males, $18-24$ years old, represent the greatest concern, as they make up the majority of the social welfare recipients. Internationally, young women are overrepresented in being NEET-later, which may be caused by teenage pregnancy and young parenthood. ${ }^{28}$ Concerns regarding NEET-status are triple regardless of gender and reasons: the cost of social welfare benefits, the lack of tax income caused by work exclusion and the public health issues related to work marginalisation and poor health. ${ }^{1}$

Minority youth, Sami young people included, are shown to be at higher risk of experiencing work marginalisation and possible social exclusion due to non-completion of upper secondary school, lower tertiary education and thereby unemployment and poor health. ${ }^{27}$ 29-32 Young adults in rural and remote Northern Norway have dropped out of upper secondary school and have higher unemployment rates than their fellow peers in the rest of Norway. ${ }^{273133}$ Young people's engagement for own education and work are influenced by parental education level and socioeconomic status (SES), such as income and job positions. $^{3435}$

The two most prevalent public health issues, mental health disorders and musculoskeletal pain problems, are costly to the quality of life for young people ${ }^{36-38}$ their families $^{3739}$ and to the society. ${ }^{40-45}$

Mental health problems in adolescence and young adulthood have been found to be associated with reduced workforce participation and increased medical welfare benefits such as sick-leave entitlements in young adulthood. ${ }^{46-48}$ Mood and anxiety disorders are the most prevalent mental health disorders resulting in long-term medical benefits in Norway, and is also closely related to adolescent musculoskeletal pain. ${ }^{49}{ }^{50}$ Adolescent musculoskeletal pain has been found to be associated with later medical and social welfare benefit receipt in young adulthood. ${ }^{51}$ Studies in adults have shown that multisite pain predicts long-term medical benefits, both overall ${ }^{40}$ and with comorbid mental health disorders. ${ }^{52}$ In Norwegians under 40 years of age, continuous sickness benefits of more than 8 weeks predict later disability pension, especially due to mental health and musculoskeletal disorders. ${ }^{53}$ Over the last decades in Norway, an increase in long-term medical benefit recipients and medical rehabilitation due to mental health disorders are found in those aged $18-29$ years. ${ }^{545}$

Research on these issues, especially in youth, can make an important contribution to public health work. A longitudinal study with emphasis on sociocultural context, musculoskeletal pain and mental health in adolescence and being NEET-later has to our knowledge 
$2003 \quad 2004 \quad 2005 \quad 2006 \quad 2007 \quad 2008 \quad 2009 \quad 2010 \quad 2011 \quad 2012$

NAAHS (2003-05)

National Insurance Registry (FD-Trygd) (2003-12)

National Education Data Base (2003-12)

15 - 16 -years-old

23-25-years-old

Figure 1 Study timeline. NAAHS, Norwegian Arctic Adolescent Health Study.

not been done previously. This study aimed to capture both emotional, relational and behavioural problems, as well as musculoskeletal pain. The predictors of experiencing NEET-later, including social relationships as well as mental and physical health, has to our knowledge not been performed previously in both majority and indigenous young people.

The first aim of this study was to explore the prevalence of young adults NEET defined by no educational engagement, long-term recipient of sickness benefit, medical and non-medical benefit receipt or long-term unemployment in an unselected population of young people in Arctic Norway.

The second aim was to determine the importance of relevant factors, such as socio-demographic factors; gender, ethnicity, parents' SES by parental education level and residency.

The third aim was to explore the prediction of self-reported mental health and musculoskeletal pain in adolescence on being NEET-later in young adulthood.

We expected that male gender, residency in northernmost and sparsely populated Finnmark county, Sami ethnicity, self-reported mental health problems and musculoskeletal problems would be associated with later NEET-status, in young adulthood, whereas higher parental education and female gender would act as protective factors.

\section{METHODS}

\section{Study design}

The Norwegian Arctic Adolescent Health Study (NAAHS) was conducted from January 2003 until January 2005. All tenth grade students in all lower secondary schools in the three northernmost Norwegian counties $(n=5887)$ were invited to participate in this study. The questionnaires were administered during a 2 -hour period in a classroom setting that was monitored by project staff; non-attending pupils completed their questionnaires at a later time. The self-reported survey consisted of several and various questions. The questionnaire was paper based and available in both the Sami and Norwegian languages.

Data on upper secondary school were missing for six students, and these were excluded from the study, leaving a working sample of 3981 students.

The Norwegian Institute of Public health and Statistics Norway carried out the registry linkage.

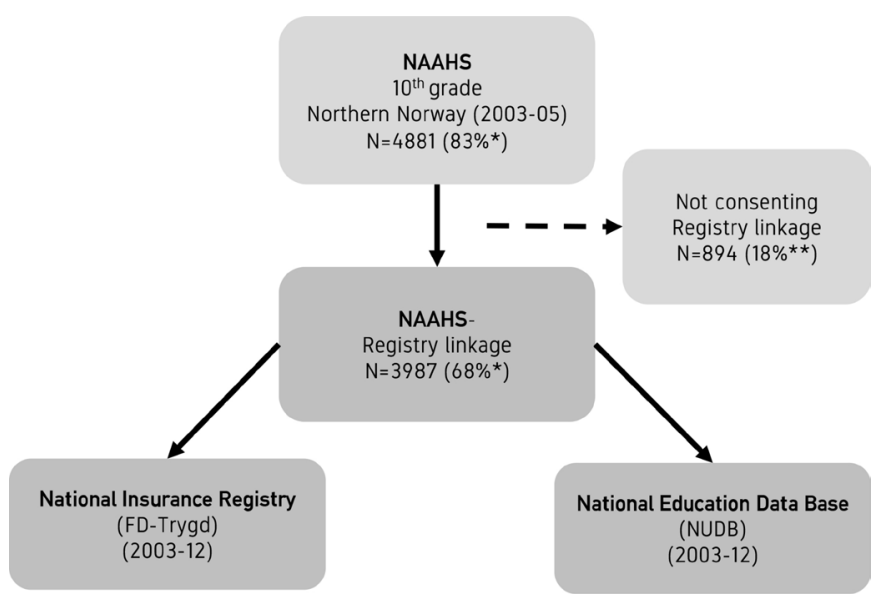

Figure 2 Flow chart for the study. *total population; ${ }^{\star *}$ NAAHS participants. FD-Trygd, National Insurance Registry; NAAHS, Norwegian Arctic Adolescent Health Study; NUDB, National Education Data Base.

The NAAHS was linked to the National Insurance Registry (FD-Trygd) and the National Education Data Base (NUDB) for the period 2003-2012. The registry databases provide information about each person's medical and social welfare benefits, unemployment and educational achievements up to 23-25 years of age for the study sample (see figure 1).

\section{Sample and participants involvement}

The participants included 4881 of the total age cohort of 5877 (response rate 83\%) adolescent 10th grade students in lower secondary school (15-16 years of age). The following response rates were observed for the three counties: Finnmark $71 \%$, Troms $82 \%$ and Nordland $88 \%$.

Of the respondents included in the sample, $50.1 \%$ were females and $49.9 \%$ were males. Four hundred and fifty out of 4881 adolescence reported Sami ethnicity, approximately $10 \%$ of the sample.

A total of 3987 (68\% of the total age cohort) of the adolescents gave their written consent to later follow-up studies including linkage to registry data, in which $9.2 \%$ of the registry sample were indigenous Sami, and $50.1 \%$ females and $49.9 \%$ males. A flow chart for the study is shown in figure 2.

\section{Patient and public involvement}

Patients and public were not involved in designing the study.

\section{Outcome measures}

NEET was defined as participants who had not completed tertiary education during the study period and either been registered as $100 \%$ unemployed for more than 1 year, or received six or more months of sickness benefits, or received six or more months of social welfare benefits during a 12-month period, or received medical rehabilitation benefits or disability pension during the entire study period. Data were based on the available data from the FD-Trygd and the NUDB. 


\section{Primary predictors}

Mental health problems

Strength and Difficulties Questionnaire $(\mathrm{SDQ})^{56}$ has a parent, teacher and a youth version. In this study, only the SDQ self-report (SDQ-S) was used. The algorithms in SDQ have problem scales for three broad-spectrum categories of problems: conduct problems, emotional problems and hyperactivity/attention problems, as well as an impact score related to family, friends, learning situation and leisure activities.

The SDQ is a brief behavioural screening questionnaire that asks 25 attributes, some positive and others negative. The 25 SDQ items are divided between five scales of five items each, generating scores for conduct problems, hyperactivity-inattention, emotional symptoms, peer problems and prosocial behaviour; all but the last one is summed to generate a total difficulties score. The extended version of the SDQ includes not just the 25 items on symptoms and positive attributes but also an impact supplement that asks whether the respondent thinks that the child or teenager has a problem, and if so, enquires further about overall distress, social impairment, burden and chronicity. All five subscales are used in this study, as well as the functional impact scale; The Prosocial Behaviour scale (SDQ-prosocial) $(\alpha=0.65)$, the Peer Problem Scale (SDQ-peer) $(\alpha=0.52)$, the Emotional Symptom Scale (SDQ-emotional) $(\alpha=0.70)$, the Conduct
Problem Scale (SDQ-conduct) $(\alpha=0.47)$ and the Hyperactivity-Inattention Scale (SDQ-hyper) $(\alpha=0.64)$.

The subscales have five items each with scores from 0 to 2 on each item, indicating; $0=$ Not correct, $1=$ Correct sometimes 2=Totally correct. The Prosocial subscale has inverse scores.

The subscale SDQ-Impact scale (SDQ-impact) $(\alpha=0.69)$ was used, where a score of 10 implies the greatest functional impairment due to mental health problems in home life, friendships, classroom activities and leisure activities. Mean scores operationalised the scales.

\section{Musculoskeletal pain}

Musculoskeletal pain was measured by 'yes/no' answers to the question from NAAHS: 'During the last 12 months have you often been troubled by pain in the head, neck/ shoulder, arms/legs/knees, abdomen or back?' Abdominal pain was excluded due to the potential confusion with menstrual pain. Headache was included based on its frequent co-existence with musculoskeletal pain and their shared mechanisms and risk factors. ${ }^{57}$ The question results in a variable ranging from zero to four pain sites.

\section{Explanatory factors from the NAAHS study}

Gender: female gender as the reference group

Residency refers to the county where the adolescent lived during lower secondary school. The three northernmost counties in Norway were compared: Nordland, Troms

Table 1 Sample characteristics of NEET-status in young adulthood and adolescent psychosocial problems and musculoskeletal pain

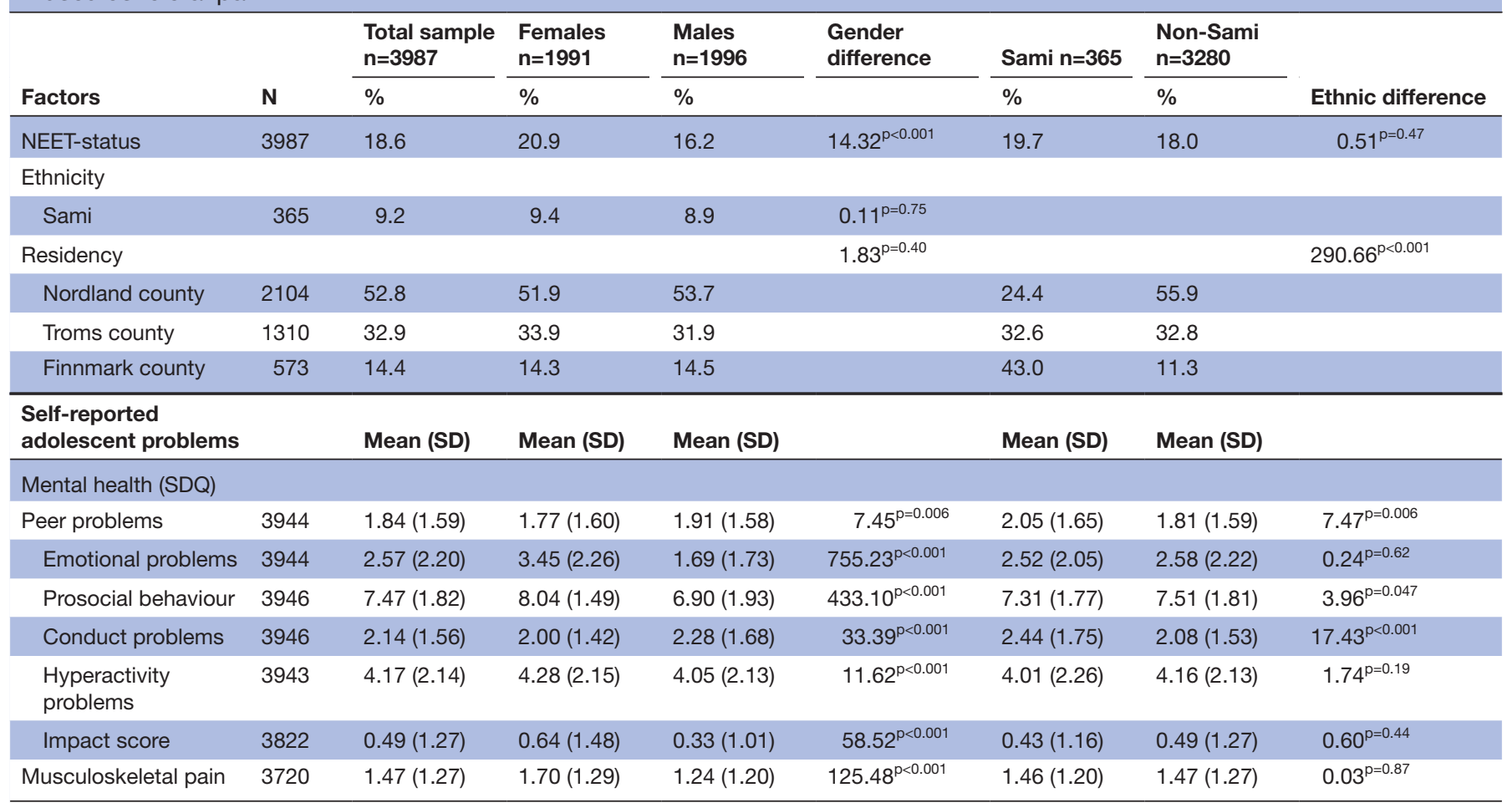

Statistical analyses: $\chi^{2}$ test and one-way analysis of variance. NEET-status data based on National Insurance Registry data (FD-Trygd). Adolescent problems based on NAAHS data (10th grade).

NEET, not engaged in education, employment or training; SDQ, Strength and Difficulties Questionnaire. 


\begin{tabular}{|c|c|c|}
\hline \multirow[b]{2}{*}{ Factors } & \multicolumn{2}{|c|}{ NEET-status } \\
\hline & Females & Males \\
\hline \multicolumn{3}{|l|}{ Ethnicity } \\
\hline Sami & $16.6 \%$ & $23.0 \%$ \\
\hline Non-Sami & $20.8 \%$ & $15.2 \%$ \\
\hline Statistical diff. & $1.62^{p=0.20}$ & $6.69^{p=0.010}$ \\
\hline \multicolumn{3}{|l|}{ Residency } \\
\hline Nordland county & $20.9 \%$ & $14.7 \%$ \\
\hline Troms county & $22.0 \%$ & $17.0 \%$ \\
\hline Finnmark county & $18.7 \%$ & $20.4 \%$ \\
\hline Statistical diff. & $1.31^{\mathrm{p}=0.52}$ & $5.93^{p=0.052}$ \\
\hline \multicolumn{3}{|l|}{ Parental education } \\
\hline Parental higher university degree & $17.1 \%$ & $8.4 \%$ \\
\hline Parental lower university degree & $18.9 \%$ & $15.0 \%$ \\
\hline Parental upper secondary education & $21.5 \%$ & $17.0 \%$ \\
\hline Parental lower secondary education & $26.4 \%$ & $23.8 \%$ \\
\hline Statistical diff. & $7.70^{p=0.053}$ & $18.11^{p<0.001}$ \\
\hline
\end{tabular}

Statistical analyses: $\chi^{2}$ test. NEET-status data based on National Insurance Registry data (FD-Trygd).

NEET, not engaged in education, employment or training.

and Finnmark, of which Finnmark is the northernmost, as well as the most remote and most sparsely populated county. Nordland county, the southernmost, has the highest number of inhabitants, and is used as the reference group.

Sami ethnicity was measured by an assessment of parents' ethnicity, Sami language competence in parents, grandparents and the participants, and ethnic self-identification. Participants who had one or more of these affiliations present were classified as having Sami ethnicity. ${ }^{58}$ Non-Sami ethnicity was used as the reference group.

Parental SES was measured by parental education level: parents' highest education was obtained from Statistics Norway's education registry, registered when the participants were aged 15-16 years. Parental education was categorised from 'lower secondary' ( $\leq 10$ th grade), 'upper secondary' ( $\leq 13$ th grade), 'lower university degree' (up to 5 years) to 'higher university degree' (5 years or more).$^{59}$ Parental higher university degree was used as the reference group.

\section{Data analysis}

Groups were compared using Pearson's $\chi^{2}$ test for categorical data, and one-way analysis of variance for continuous data. Logistic regression was used for the multivariable analyses for the association with later NEET-status, stratified by gender. Based on a $10 \%$ outcome rate in a non-exposed group then the following OR should be considered as small $(\mathrm{OR}=1.46)$, medium $(\mathrm{OR}=2.50)$ and large $(\mathrm{OR}=4.14)$ effect sizes. ${ }^{60}$ Evaluation of the multivariable models explained variance was done by Cohen's criteria
$\left(\mathrm{R}^{2}\right)$ : $2 \%-13 \%$ is small, $13 \%-26 \%$ is medium and $\geq 26 \%$ is large. ${ }^{61}$ Two-sided $\mathrm{p}$ values $<0.05$ are taken to indicate statistical significance. Due to multiple hypotheses, $\mathrm{p}$ values between 0.01 and 0.05 should be interpreted with caution.

We also examined for interaction terms between gender, residency and adolescent problems, as well as Sami ethnicity, residency and adolescent problems. SPSS V.22 was used for all analyses and the statistical significance level was set to 0.05 .

\section{RESULTS}

NEET-status in young adulthood was significantly higher among females (20.9\%) than among males (16.2\%) (table 1). Ethnic differences occurred as being NEET among Sami males was significantly higher than among non-Sami males, $23.0 \%$ and $15.2 \%$ respectively (table 2 ). Sami females experienced NEET-status to a lower degree $(16.6 \%)$ than non-Sami females $(20.8 \%)$. The difference was however, not statistically significant for females (table 2).

A strong geographical trend occurred between young males from the counties of Nordland, Troms and Finnmark. Males from the northernmost Finnmark county showed a higher rate of experiencing NEET-status ( $\mathrm{p}=0.052)$ than among male counterparts from Nordland and Troms counties (table 2). This geographical trend was not found among females. Parental education and later NEET-status among females was nearly significant $(\mathrm{p}=0.053)$, while the association was highly significant among males (table 2).

The multivariable analyses of the association between sociodemographic factors, adolescent mental health problems, adolescent musculoskeletal pain and being NEET-later are presented in table 3. Participants with parents with a lower secondary education level had a significantly higher risk of experiencing NEET-status at all analytical levels for both genders, compared with participants with parents with a higher university degree. Male participants with parents with upper secondary education level showed a similar association on all analytical levels of significantly higher NEET-status, compared with male participants with parents with a higher university degree (table 3).

Among the sociodemographic variables, Sami ethnicity was a significant predictor for more NEET-status in males, but non-significant for being categorised as NEETs later in females (table 3 ). In both genders the sociodemographic variables alone accounted for a small percentage of the explained variance (between $1 \%$ and $2 \%$ ) of later NEET-status.

For both males and females, the explained variance increased with $6 \%-7.3 \%$ when adolescent mental health and musculoskeletal pain were included in the model. In the unadjusted analyses, all types of mental health behaviour, except for prosocial behaviour, were significantly associated with being NEET-later for both genders. 


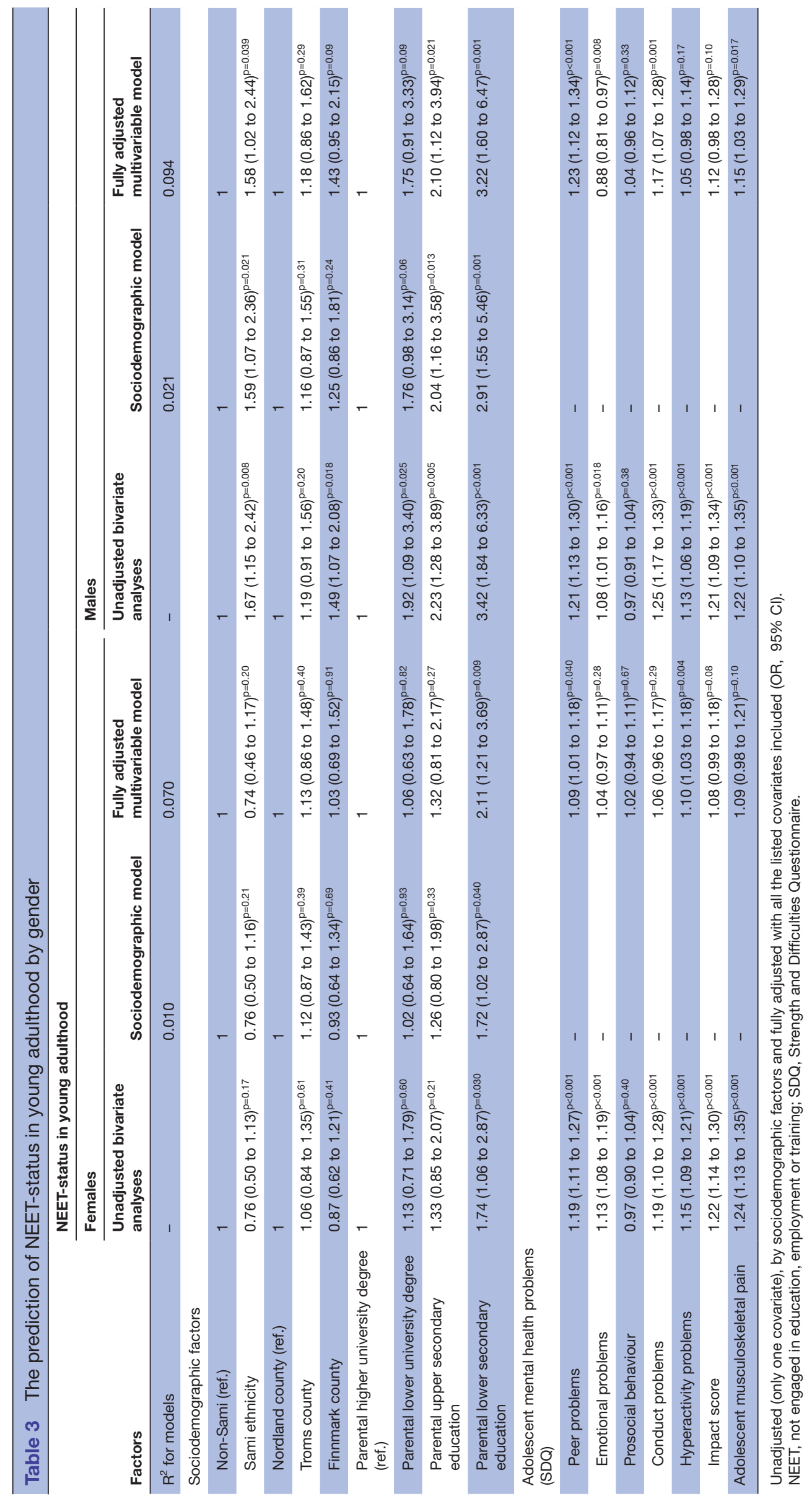


In both genders, peer problems were a significant predictor of NEET-status both in the unadjusted and fully adjusted analyses. However, in the fully adjusted model the impact of the other mental health problems on experiencing NEET- status differed between males and females. In females, hyperactivity was the only remaining significant predictor of later NEET-status, while in males conduct problems and musculoskeletal problems were associated with being NEET later. Males who reported more emotional problems experienced significantly less NEET-status when controlled for all other predictors. Prosocial behaviour and daily functioning (SDQ impact) was not associated with later NEET status for any gender.

We found no significant interactions for later NEETstatus for either Sami ethnicity and residency, or gender and residency by the adolescent problems at the 0.05 level.

\section{DISCUSSION}

\section{Main findings}

In this study, mental health problems and musculoskeletal pain in adolescence were associated with experiencing being NEET-later. Lower parental education was found to be significantly associated with NEET-status in young adulthood. The predictive effect of gender for being NEET later were minor in this study, although female NEET-status was significantly higher than among males. Ethnic differences occurred as being NEET among Sami males was significantly higher than among non-Sami males, while Sami females experienced NEET-status to a lower degree than majority female peers.

\section{Methodological strengths and limitations}

The main strength of this study is the linkage of an unselected population-based study with a high response rate to registry data, enabling analyses of predictors of later NEET. The study had an equal gender distribution and a high participation rate, and indigenous Sami were represented almost equally in the survey and in the consentbased follow-up study. The NAAHS participants not consenting registry linkage did not differ in sociodemographics or mental health from the linkage participants, thereby strengthening its generalisability. ${ }^{62}$ The longitudinal study linked cross-sectional adolescent self-reported data of a broad spectre of predictors (SES, sociocultural factors, daily functioning, mental and physical health) among adolescents aged 15-16years and NEET-status among young people aged 23-25 years (8-10 years after survey).

Reliability and validity of brief scales, such as the SDQ, can be questioned also in this study. ${ }^{63}$ Cronbach's alpha was applied as a measure of internal consistency reliability, with a value of. 70 or more considered reliable. The Emotional Symptoms Scale (SDQ-emotions), the Prosocial Behaviour Scale (SDQ-prosocial), the SDQ-Impact Scale (SDQ-impact) and, the Hyperactivity Scale (SDQ-hyper) could be considered reliable, while the
Conduct Problems (SDQ-conduct) and Peer Problem Scales (SDQ-Peer) had a lower value, which can question the validity of these scales. SDQ-peer as a psychometric tool is also questioned for certain ethnic groups of children due to the lack of sociocultural sensitivity. Williamson $e t a l^{64}$ exemplifies the poor fit by the lack of questions of connection to extended family, ethnic identity and the impact and experience of racism. The results for peer problems in this study should therefore be interpreted with caution.

In this registry-linked study we were limited to only one cross-sectional study and the findings in this study are assumed to be influenced by other or more present explanatory factors, reflected by the relatively lower explained variances for later NEET. The explained variance of the multivariable models might be considered to be low; however, explained variance is a relative value, dependent on the nature of the associations examined. In outcomes with multiple determinants, the size of the explained variance is limited by nature.

The survey was answered during school time, and in a classroom setting. The cluster effect may influence the responses given.

The concept of being NEET is questioned, ${ }^{10}$ and has limitations. ${ }^{9}$ However, NEET-status is a tool with an outcome of primary interest which will include changes in objective status. A transition from NEET-status to non-NEET-status, is a change from disengagement to engagement ${ }^{12}$ which can have important implications for young people's quality of life and health. ${ }^{121}$

\section{Interpretation of the results and comparison to previous findings}

To our knowledge, this study is the first longitudinal study to explore the prediction of adolescent musculoskeletal pain and mental health problems on being NEET in young adulthood in a representative sample of indigenous and non-indigenous people in the Arctic.

The proportion of participants who were classified with NEET-status in young adulthood was high, at $18.6 \%$. In spite of a high living standard, Norway has a high incidence of sickness absence and disability caseload in the OECD. ${ }^{25}$ Eckhoff $e t a l^{51}$ found that $17.2 \%$ of the participants in the NAAHS study had received any level of social welfare benefits during the entire study period of up to 10 years. The large number of recipients among a cohort of young people is worrying. The foundation of a sustainable welfare society is its working force. ${ }^{15}{ }^{16}$ Female NEET-experience in this study was found to be significantly higher than male NEET-experience. This is in accordance with numbers from OECD. ${ }^{28}$ However, female NEET-status within the OECD is associated with teenage pregnancy and young parenthood. ${ }^{65}$ Norway has a low prevalence of teenage pregnancy and has means related to bringing young mothers into education and work, both through student loans, social housing, social entitlements, kindergartens and benefits for young single mothers and young parents. ${ }^{1527}$ There could be other explanations for the 
higher proportions of female NEET-status, as national statistics show that young females report difficulties in living conditions such as loneliness, inactive lifestyle and mental health problems. ${ }^{26}$

Several studies have shown that females in ethnic minorities and Indigenous people experience poorer health and NEET-status to a larger extent than their majority peers. ${ }^{3266}$ Our study, however, did not in general confirm such findings as Sami females were less likely than majority peers to experience NEET-status in young adulthood. Recent studies among the NAAHS cohort show that the indigenous Sami youth do not differ much from their majority peers in completing upper secondary school, ${ }^{31}$ and that Sami minority young people complete tertiary education equally as much, or more, than majority Norwegians. ${ }^{30}$ In this study Sami males however, significantly experienced more NEET-status in young adulthood. This supports earlier findings of lower educational aspirations, ${ }^{29}$ and higher drop-out rates from upper secondary school in Sami young males than in majority male peers. ${ }^{31}$ As education is an important key factor for good health and work inclusion ${ }^{32}$ this risk position of indigenous Sami males in Arctic Norway is concerning.

The finding that lower levels of parental education and peer problems in adolescence across gender were associated with later NEET-status in young adulthood indicate the importance of relational and environmental conditions on young peoples' education and work marginalisation, ${ }^{10}$ as well as alienation from community and authority. ${ }^{2}$ Garg et $a l^{67}$ suggested that family background predicts educational aspirations with respect to academic self-concept, as highly educated parents can influence their children when it comes to higher education, and thereby prevent NEET-experience. Several studies suggest how employment-rich networks and community-based neighbourhood influences young people's access to work, income, health and well-being ${ }^{1068}$

The findings that peer problems and hyperactivity in females were associated with being NEET-later, is supported by previous findings in the NAAHS study among young females when it comes to high school dropout $^{31}$ and partly for tertiary education. ${ }^{30}$ Myklestad et $a b^{69}$ suggest that poor mental health contributes to high school dropout or lower educational achievement, ${ }^{30} 31$ and later work marginalisation by disability pension. ${ }^{70}$ SDQ's hyperactivity scale used in this study also includes attention problems, which are shown to cause cognitive problems in school. ${ }^{71}$ The effect of poor mental health on educational achievement, but also work marginalisation was also shown for males in this study, as adolescent conduct problems and musculoskeletal pain were found to be associated with later NEET-status in males. However, the findings that male emotional problems were significantly associated with less NEET-status later support similar findings among females with emotional problems, who dropped less out of upper-secondary school ${ }^{31} \mathrm{com}$ pared with other female peers. Breslau et $a l^{72}$ suggest the mechanisms of internalising symptoms or emotional problems, might not influence the ability to complete education, and thereby training or work. It is reasonable to assume that structured activities as education and employment can be completed in spite of experiencing mood, depression or anxiety problems.

\section{CONCLUSIONS}

Young people whose parents had lower educational status and those with disturbed peer relations were at greater risk of NEET-status. Mental health problems and musculoskeletal pain in adolescence were associated with later NEET-status. Gender differences in predictors for experiencing NEET-later were minor in this study, although female NEET-status was significantly higher than among males. Sami ethnicity was a significant predictor for more NEET-status in males, but non-significant for being categorised as NEETs later in females. Particular emphasis must be placed on supporting young people struggling with mental and physical health problems to avoid later NEET-status. Targeted means can be effective, helping young adults achieve desirable education and thereby work, income, health and well-being. Social policy measures have to be diversified, tackling different issues along the pathway to employment and paying attention to vulnerable groups, to enable young people education, work and income.

Contributors EVB has contributed to the concept and design of the study, the acquisition of registry data, analysis and interpretation of data, drafting and revising the manuscript. CE has contributed in the analysis and interpretation of data, critical review and revision of the manuscript. SK has been the project manager of the Norwegian Arctic Adolescent Health Study, being responsible for the content of the questionnaire and the data collection. SK has supervised all processes of drafting the manuscript, in the interpretation of data and in revising the manuscript.All authors have read and approved the revised manuscript.

Funding The work was funded by the SpareBank 1 Nord-Norge Donations Fund and the Sami Norwegian National Advisory Unit on Mental Health and Substance Use (SANKS), in addition to the Department of Clinical Medicine, University of Tromsoe, The Arctic University of Norway as well as Regional Centre for Child and Youth Mental Health and Child Welfare (RKBU Central Norway), Department of Mental Health, Faculty of Medicine and Health Sciences, NTNU.

Disclaimer The researchers were independent of the funding bodies.

\section{Competing interests None declared.}

Patient consent for publication Not required.

Provenance and peer review Not commissioned; externally peer reviewed.

Data sharing statement This epidemiological study consists of data not traceable. All data are erased by 31 December 2017. No additional data are available.

Open access This is an open access article distributed in accordance with the Creative Commons Attribution Non Commercial (CC BY-NC 4.0) license, which permits others to distribute, remix, adapt, build upon this work non-commercially, and license their derivative works on different terms, provided the original work is properly cited, appropriate credit is given, any changes made indicated, and the use is non-commercial. See: http://creativecommons.org/licenses/by-nc/4.0/.

\section{REFERENCES}

1. Mawn L, Oliver EJ, Akhter N, et al. Are we failing young people not in employment, education or training (NEETs)? A systematic review and meta-analysis of re-engagement interventions. Syst Rev 2017;6:16.

2. Thompson R, Russell L, Simmons R. Space, place and social exclusion: an ethnographic study of young people outside education and employment. J Youth Stud 2014;17:63-78. 
3. Olsen T, Tägtström J, Bremberg S, et al. For det som vokser: Unge, psykisk uhelse og tidliguførepensjonering i Norden. En antologi 2013.

4. Social Exclusion Unit CO, Great Britain. Bridging the gap: new opportunities for 16-18 year olds not in education, employment or training. 1999.

5. Lunsing W. The Creation of the social category of NEET (Not in Education, employment or training): Do NEET Need This? Soc Sci Jpn J 2007;10:105-10.

6. Kato TA, Shinfuku N, Sartorius N, et al. Are Japan's hikikomori and depression in young people spreading abroad? Lancet 2011;378:1070.

7. Li TM, Wong PW. Youth social withdrawal behavior (hikikomori): a systematic review of qualitative and quantitative studies. Aust N Z J Psychiatry 2015;49:595-609.

8. Teo AR. A new form of social withdrawal in Japan: a review of hikikomori. Int J Soc Psychiatry 2010;56:178-85.

9. Furlong $A$. Not a very NEET solution representing problematic labour market transitions among early school-leavers. Work, employment \& society $2006 ; 20: 553-69$.

10. Simmons R, Russell L, Thompson R. Young people and labour market marginality: findings from a longitudinal ethnographic study. $J$ Youth Stud 2014;17:577-91.

11. Mascherini M, Salvatore L, Meierkord A, et al. NEETs: Young people not in employment, education or training: Characteristics, costs and policy responses in Europe. Luxembourg: Publications Office of the European Union, 2012

12. Oliver EJ, Mawn L, Stain HJ, et al. Should we 'hug a hoodie'? Protocol for a systematic review and meta-analysis of interventions with young people not in employment, education or training (socalled NEETs). Syst Rev 2014;3:73.

13. OECD. Jobs for youth. OECD: Paric, 2008.

14. OECD. Society at a Glance. 2016

15. Hatland A, Kuhnle S, Romøren TI. Den norske velferdsstaten: Gyldendal, 2011

16. Terum $\mathrm{LI}$, Hatland A. Sysselsetting og trygd under arbeidslinja. Søkelys på arbeidslivet 2014;31:3-22.

17. Daly M, Rake K. Gender and the welfare state: Care. John Wiley and Sons: Work and welfare in Europe and the USA, 2003.

18. Solow RM. Work and welfare: Princeton University Press, 2009.

19. France A, Wiles P. Dangerous futures: social exclusion and youth work in late modernity. Social Policy and Administration 1997;31:59-78

20. Shildrick T, Blackman S, MacDonald R, et al. Young people, class and place. J Youth Stud 2009;12:457-65.

21. Aldabe B, Anderson R, Lyly-Yrjanainen M, et al. Contribution of material, occupational, and psychosocial factors in the explanation of social inequalities in health in 28 countries in Europe. Journal of Epidemiology \& Community Health 2011;65:102517:1123-31.

22. Normann T, Rønning E, Nørgaard E. Utfordringer for den nordiske velferdsstaten-sammenlignbare indikatorer [Challenges for the Nordic Welfarestate-comparable indicators]. Copenhagen: Nordic SocialStatistical Committee (NOSOSKO), 2009

23. Strøm IF, Thoresen S, Wentzel-Larsen T, et al. Exposure to life adversity in high school and later work participation: a longitudinal population-based study. J Adolesc 2013;36:1143-51.

24. OECD. OECD better life index. 2012.

25. Index BL. OECD better life index. 2012.

26. SSB. Sosialhjelp og levekår i Norge, Statistiske analyser 139 , Statistisk sentralbyrå. 2012 http://www.ssb.no/sosiale-forhold-ogkriminalitet/artikler-og-publikasjoner/sosialhjelp-og-levekaar-i-norge

27. SSB. KOSTRA nøkkeltall. 2004-2014 www.ssb.no

28. Valle RC, Normandeau S, Gonzalez GR. Education at a glance interim report: update of employment and educational attainment indicators. 2015.

29. Bania EV, Eckhoff C, Kvernmo S. The influence of mental health, psychosocial factors, and educational skills on the educational aspirations of indigenous sámi and non-indigenous adolescents in the arctic. Scand J Child Adolesc Psychiatr Psychol 2015;3:169-79.

30. Bania EV, Kvernmo SE. Tertiary education and its association with mental health indicators and educational factors among Arctic young adults: the NAAHS cohort study. Int $J$ Circumpolar Health 2016;75:32086

31. Bania EV, Lydersen S, Kvernmo S. Non-completion of upper secondary school among female and male young adults in an Arctic sociocultural context; the NAAHS study. BMC Public Health 2016;16:1-11.

32. Anderson I, Robson B, Connolly M, et al. Indigenous and tribal peoples' health (The Lancet-Lowitja Institute Global Collaboration): a population study. The Lancet 2016;388:131-57.

33. SSB. Throughput of pupils in upper secondary education, 20102015. 2016 http://ssbno/en/utdanning/statistikker/vgogjen/aar/
34. Sirin SR. Socioeconomic status and academic achievement: a metaanalytic review of research. Rev Educ Res 2005;75:417-53.

35. Putnam R. Our kids. The American dream in crisis New York. New York: Simon and Schuster, 2015.

36. Hoftun GB, Romundstad PR, Zwart JA, et al. Chronic idiopathic pain in adolescence-high prevalence and disability: the young HUNT Study 2008. Pain 2011;152:2259-66.

37. Hunfeld JA, Perquin CW, Duivenvoorden HJ, et al. Chronic pain and its impact on quality of life in adolescents and their families. $J$ Pediatr Psychol 2001;26:145-53.

38. Konijnenberg AY, Uiterwaal CS, Kimpen JL, et al. Children with unexplained chronic pain: substantial impairment in everyday life. Arch Dis Child 2005;90:680-6.

39. Lewandowski AS, Palermo TM, Stinson J, et al. Systematic review of family functioning in families of children and adolescents with chronic pain. J Pain 2010;11:1027-38.

40. Kamaleri Y, Natvig B, Ihlebaek CM, et al. Does the number of musculoskeletal pain sites predict work disability? A 14-year prospective study. Eur J Pain 2009;13:426-30.

41. Goodman A, Joyce R, Smith JP. The long shadow cast by childhood physical and mental problems on adult life. Proceedings of the National Academy of Sciences 2011;108:6032-7.

42. Organization WH. Caring for children and adolescents with mental disorders: Setting WHO directions. 2003

43. Sleed M, Eccleston C, Beecham J, et al. The economic impact of chronic pain in adolescence: methodological considerations and a preliminary costs-of-illness study. Pain 2005;119:183-90.

44. Groenewald CB, Palermo TM. The price of pain: the economics of chronic adolescent pain. Pain 2015:5:61-4.

45. Patel V, Flisher AJ, Hetrick S, et al. Mental health of young people: a global public-health challenge. Lancet 2007;369:1302-13.

46. De Ridder KA, Pape K, Cuypers K, et al. High school dropout and long-term sickness and disability in young adulthood: a prospective propensity score stratified cohort study (the Young-HUNT study). BMC Public Health 2013;13:941.

47. Pape K, Bjørngaard JH, Holmen TL, et al. The welfare burden of adolescent anxiety and depression: a prospective study of 7500 young Norwegians and their families: the HUNT study. BMJ Open 2012;2:e001942.

48. Sagatun Å, Heyerdahl S, Wentzel-Larsen T, et al. Medical benefits in young adulthood: a population-based longitudinal study of health behaviour and mental health in adolescence and later receipt of medical benefits. BMJ Open 2015;5:e007139.

49. Mangerud WL, Bjerkeset $O$, Lydersen S, et al. Chronic pain and painrelated disability across psychiatric disorders in a clinical adolescent sample. BMC Psychiatry 2013;13:272.

50. Eckhoff C, Kvernmo S. Musculoskeletal pain in arctic indigenous and non-indigenous adolescents, prevalence and associations with psychosocial factors: a population-based study. BMC Public Health 2014; $14: 617$

51. Eckhoff C, Straume B, Kvernmo S. Multisite musculoskeletal pain in adolescence as a predictor of medical and social welfare benefits in young adulthood: the Norwegian arctic adolescent health cohort study. Eur J Pain 2017;21:1697-706.

52. Øverland S, Harvey SB, Knudsen AK, et al. Widespread pain and medically certified disability pension in the hordaland health study. Eur J Pain 2012;16:611-20.

53. Gjesdal S, Haug K, Ringdal P. SE Vollset og JG Mæland (2005)“Risiko for uførepensjonering blant unge langtidssykemeldte". Tidsskrift Nor Lægeforening 2005;125:1801-5.

54. SBoO T. Ung uførhet og psykisk sykdom: Arbeid og velferd, 2015.

55. Brage S, Bragstad T. Unge på arbeids-og helserelaterte ordninger. Oslo: Arbeids-og velferdsdirektoratet Oslo, 2011

56. Goodman R, Meltzer H, Bailey V. The strengths and difficulties questionnaire: a pilot study on the validity of the self-report version. Eur Child Adolesc Psychiatry 1998;7:125-30.

57. Fumal A, Schoenen J. Tension-type headache: current research and clinical management. Lancet Neurol 2008;7:70-83.

58. Kvernmo S, Heyerdahl S. Ethnic identity in aboriginal Sami adolescents: the impact of the family and the ethnic community context. J Adolesc 1996;19:453-63.

59. SSB. Norwegian standard classification of education (NOS C 751). Oslo: Statistisk sentralbyrå/Statistics Norway, 2003.

60. Chen H, Cohen P, Chen S. How Big is a Big Odds Ratio? Interpreting the magnitudes of odds ratios in epidemiological Studies. Commun Stat Simul Comput 2010;39:860-4.

61. Cohen J. Statistical power analysis for the behavioural sciences. Hillsdale, NJ: Erlbaum, 1988.

62. Eckhoff C, Straume B, Kvernmo S. Multisite musculoskeletal pain in adolescence and later mental health disorders: a population-based 
registry study of Norwegian youth: the NAAHS cohort study. BMJ Open 2017;7:e012035.

63. van Widenfelt BM, Goedhart AW, Treffers PD, et al. Dutch version of the Strengths and Difficulties Questionnaire (SDQ). Eur Child Adolesc Psychiatry 2003;12:281-9.

64. Williamson A, McElduff $P$, Dadds $M$, et al. The construct validity of the strengths and difficulties questionnaire for aboriginal children living in Urban New South Wales, Australia. Aust Psychol 2014;49:163-70.

65. Sonnet A. Off to a good start? Jobs for youth: OECD, 2010.

66. Kao G, Tienda M. Educational aspirations of minority youth. Am J Educ 1998;106:349-84.

67. Garg R, Melanson S, Levin E. Educational aspirations of male and female adolescents from single-parent and two biological parent families: a comparison of influential factors. $J$ Youth Adolesc 2007:36:1010-23.

68. White RJ, Green AE. Opening up or Closing down Opportunities?: the role of social networks and attachment to place in informing young peoples' attitudes and access to training and employment. Urban Stud 2011;48:41-60.

69. Myklestad I, Røysamb E, Tambs K. Risk and protective factors for psychological distress among adolescents: a family study in the Nord-Trøndelag Health Study. Soc Psychiatry Psychiatr Epidemiol 2012;47:771-82.

70. Lassemo E, Sandanger I, Nygård JF, et al. Predicting disability pension - depression as hazard: a 10 year population-based cohort study in Norway. Int J Methods Psychiatr Res 2016;25:12-21.

71. Koskelainen M, Sourander A, Kaljonen A. The strengths and difficulties questionnaire among finnish school-aged children and adolescents. Eur Child Adolesc Psychiatry 2000;9:277-84.

72. Breslau J, Miller E, Joanie Chung WJ, et al. Childhood and adolescent onset psychiatric disorders, substance use, and failure to graduate high school on time. J Psychiatr Res 2011;45:295-301. 